\title{
Childhood Ovarian Mature Teratoma
}

National Cancer Institute

\section{Source}

National Cancer Institute. Childhood Ovarian Mature Teratoma. NCI Thesaurus. Code C6548.

A mature teratoma that arises from the ovary and occurs in children. 